\title{
Um estudo bibliográfico sobre os fatores determinantes na escolha de uma instituição de ensino superior
}

O presente estudo tem como objetivo analisar os fatores que influenciam as pessoas na escolha de uma IES, em termos específicos descrever o cenário da educação superior no Brasil, descrever os aspectos centrais do comportamento do consumidor, analisa os fatores na escolha de uma IES, A pesquisa foi desenvolvida com os artigos que estão disponíveis nas plataformas de artigos Google Acadêmico e Scielo. O estudo é de natureza básica, exploratória, com abordagem qualitativa. O resultado esperado para esse estudo é ajudar as pessoas a terem um planejamento mais adequado na escolha de uma IES para quem deseja cursar alguma graduação, e com isso as IES vejam as dificuldades enfrentadas pelas pessoas que estão ou vão entrar em uma IES, e auxiliem os mesmo para que eles tenham uma facilidade maior de ingressar na mesma.

Palavras-chave: Educação; Ensino Superior; Graduação.

\section{A bibliographic study on determining factors in choosing a higher education institution}

\begin{abstract}
This study aims to analyze the factors that influence people in choosing a HEI, in specific terms describe the scenario of higher education in Brazil, describe the central aspects of consumer behavior, analyzes the factors in choosing a HEl, A The research was developed with articles that are available on the Google Scholar and Scielo article platforms. The study is basic, exploratory, with a qualitative approach. The expected result for this study is to help people to have a better planning in choosing an HEl for those who wish to study, and thus the HEI see the difficulties faced by people who are or are going to enter a HEI, and help the same so that they have a greater ease of joining it.
\end{abstract}

Keywords: Education; Higher education; University graduate.

Topic: Marketing e Estratégias Mercadológicas

Reviewed anonymously in the process of blind peer.
Received: $14 / 01 / 2019$

Approved: 25/04/2019
Francisco Da Silva Gomes (iD

Centro Universitário Vale do Salgado, Brasil

http://lattes.cnpq.br/4655820258537460

franksgomes10@gmail.com

Antonio Raniel Silva Lima

Faculdade Vale do Salgado, Brasi

http://lattes.cnpq.br/3467170484393980

http://orcid.org/0000-0002-9563-2160

tomraniel@outlook.com
Referencing this:

GOMES, F. S.; LIMA, A. R. S.. Um estudo bibliográfico sobre os fatores determinantes na escolha de uma instituição de ensino superior. Entrepreneurship, v.4, n.1, p.1-7, 2020. DOI: http://doi.org/10.6008/CBPC2595-4318.2020.001.0001 


\section{INTRODUÇÃO}

Como mercado de trabalho está ficando cada vez mais exigente, as pessoas procuram especializações em diversas áreas para que eles consigam um emprego que possa atender a necessidades de consumo, eles então devem buscar meios de aprimorar seus conhecimentos e crescer profissionalmente, então eles decidem ingressar em uma IES.

Como existem vários fatores importantes para que dos futuros universitários possam ingressar em uma universidade, existem também os que impedem de cursar uma IES, uma delas é a localização onde se encontra a instituição, tem a questão financeira, também existem as instituições perto da localidade do estudante, mas que não oferta o curso que almeja estudar e por conta desses fatores e entre outros muitos jovens não conseguem cursar uma instituição de ensino. A pergunta norteadora desta pesquisa é: quais são os principais fatores que influenciam aos pré-universitários na escolha de uma IES?; em termos específicos, analisar os fatores que levam as pessoas a escolher uma Instituição de Ensino Superior. Descrever o cenário atual do ensino superior no Brasil; descrever os aspectos centrais do comportamento do consumidor,

Para a realização desse estudo foi necessário identificar um problema que é pouco abordado, que são os pré-universitários, assim que chegam na sua reta final do ensino médio têm enormes dificuldades na escolha de uma IES, para que eles não fiquem desnorteados na hora de escolher uma universidade. Esse estudo vai analisar as dificuldades enfrentadas por eles e assim contribuir na tomada de decisão dos mesmos. Foi necessário procurar artigos que abordassem sobre essa temática, além de outros temas que contribuíram para a construção desse trabalho, pesquisando esses artigos foi possível identificar vários fatores que influenciam os estudantes na preferência de uma instituição.

Portanto, é de extrema transcendência conhecer esses fatores, assim os alunos e as pessoas que já tenham concluído o ensino médio não vão ter inseguranças na sua decisão, esses fatores vão auxiliar os tanto os estudantes como as pessoas que queiram ingressar em uma IES a fazer um planejamento adequado, coletando dados necessários para que eles conheçam o método de funcionamento da instituição antes mesmo de ingressar, assim, os futuros universitários já vão com o conhecimento necessário da instituição para não ficarem desnorteados no ensino superior. Conhecendo essas dificuldades enfrentadas, tanto com os estudantes que vão concluir o ensino médio como as pessoas que já concluíram e desejam ingressar novamente.

\section{REVISÃO TEÓRICA}

\section{Educação Superior no Brasil}

As pessoas procuram especialização para enfrentar o mercado de trabalho. O mercado de trabalho vem se transformando com as mudanças que vem acontecendo como os fatores externos como a tecnologia e a economia e isso vem afetando as pessoas constantemente exigido mais das classes trabalhadora, onde isso vai implica direto no mercado educacional.

O mercado educacional está em constante reformas é apresentado muitas concorrências. De acordo 
com Aléssio et al. (2010), no Brasil, vive-se uma disputa muito alta no mercado educacional, principalmente as instituições de ensino superior que fazem parte da rede privada, dessa maneira elas são obrigadas a criarem novos métodos e formas para atrair novos estudantes.

Com os programas sociais que foram criados o número de matriculas no ensino superior aumentou, de acordo com INEP (2018). No ano de 2018 o país 8,45 milhões de pessoas estavam cursando alguma graduação em uma IES. Esse número representa um aumento de 44,6\% em 10 anos. 6,37 milhões dessas matrículas estão distribuídas em 2.238 instituições de que fazem parte da rede privada, já 2,08 milhões das matrículas estão distribuídas nas 299 instituições da rede pública de ensino.

O censo educacional de ensino superior realizado pelo o mesmo apresentou que no ano de 2017 o estado de São Paulo é o que mais oferta cursos de ensino superior no país, ofertando ao todo 8.118 cursos. Para monitora a educação o governo do Brasil criou em 2014 programa PNE 'Plano Nacional de Educação' que tem como objetivo determinar diretrizes, metas e estratégias para a política educacional no período de 2014 a 2024. Contendo ao todo 20 metas é uma dessas metas que é a número 12 é expandir a educação superior para que as pessoas tenham mais facilidade de ingressar em uma universidade entre outros.

Os cursos mais procurados no Brasil no ano de 2015 no Sisu foram os cursos de Administração, Direito, Pedagogia, Medicina, Educação Física, Engenharia Civil, Ciências Biológicas, Enfermagem, Psicologia, Ciências Contábeis, esses cursos eram mais procurados por conta do mercado. Segundo INEP (2018) apresentou que ano de 2017, no Brasil, havia ao todo 2.448 instituições de ensino superior sendo que 296 instituições fazem parte da rede pública que são representados em $41,9 \%$ estaduais, $36,8 \%$, federais e $21,3 \%$, municipais e 2.152 que é composta pela rede privada que é representada por 87,9\% (INEP, 2018).

Os cursos de bacharelado é o que mais predominam no mercado educacional sempre tem o número mais alto de ingresso no ano de 2017 teve 1.940 .059 representando 61\%, em seguida o de Licenciatura com 649.137 representado com 20\%, é por último os cursos tecnológicos com 617.317 representado 19\% (INEP, 2018).

A educação é uma área estratégica, pois constitui condição essencial para a construção de uma sociedade justa e democrática. Nesse sentido, a oferta de educação básica e superior, com eficiência, qualidade e equidade, repercutirá decisivamente no desempenho econômico do País, com taxas mais elevadas de crescimento e por longo período de estabilidade, na democratização do ensino e na inclusão social. (RODRIGUES, 2016)

O censo educacional superior em 2016, no Ceará as instituições públicas é que concentra o número mais alto de matrículas de estudantes esses dados são representado por $78,25 \%$ da rede estadual, é $82,82 \%$ da rede federal, já nas instituições de rede privada esse número e um pouco menor representava $70,79 \%$ de alunos matriculados, por outro lado a rede estadual é que lidera o número de trancamentos de matrículas esse número representava $18,32 \%$ em e seguida vem as IES da rede privada com $13,4 \%$ e por último as IES da rede federal com $4,32 \%$.

Marques (2015) explica porque é de suma importância que as IES coloquem novos modelos diferenciais no mercado educacional para que assim tenham a captação de novos ingressos e que eles permaneçam na instituição durante toda a sua vida acadêmica, com isso a instituição saberá que os fatores que foram aplicados para influência foram fortes bastante devido a permanência do aluno na instituição. 
Dessa forma as pessoas terão uma análise de como está o cenário atual mercado educacional, e assim terá um planejamento mais amplo na escolha de um curso de ensino superior. $O$ ensino superior é umas das etapas mais importantes na vida, pois ele é responsável para que as pessoas escolham uma área profissional para se especializar, para atuar no mercado de trabalho.

\section{Comportamento do Consumidor}

O consumidor são pessoas que procura produtos ou serviços para atender suas necessidades ou desejos que variam de acordo com seu gosto, onde elas compram um produto e depois os descartam fazendo isso de acordo com os três processos do consumo. "Comportamento do consumidor, se refere ao comportamento de compra dos consumidores finais, aquelas pessoas que adquirem produtos para uso pessoal ou doméstico, e não para fins comerciais" (PRIDE et al., 2001).

Larentis (2009). Ressalta que o nível de consumo da sociedade vem se elevando constantemente ao passar dos tempos, a partir disso nascem as empresas para atender essas necessidades dos consumidores, elevando assim o número de concorrência é aumentando a diversidade de escolha do consumidor. Segundo Bergamo et al. (2010) para conseguir a preferencias dos consumidores é preciso compreender melhor seu comportamento de compra, de modo a tornar possível o desenvolvimento de estratégias de comunicação mais eficientes.

De acordo com o Sebrae (2019). Conhecer o comportamento do consumidor, traz um diferencial para organização da forma em que eles se comportam no mercado, através disso vai se uma boa hora de colocar os planos estratégicos da empresa em prática, através dessa maneira saberão quais são os principais fatores que os influenciam na sua tomada de decisão e trarão um desenvolvimento organizacional. $\mathrm{O}$ autor ainda destaca que os fatores são divididos em tópicos que são os culturais, sociais, pessoais e psicológicos, e dentro deles estão os subtópicos.

O fator Culturais está dividido em três subtópicos, que é o cultural, a subcultura é a classe social. Cultural: os consumidores acabam captando valores e costumes, crenças de grupos sociais que acabam sendo uma das influências do consumo; Subcultura: está presente dentro das sociedades e não se desvinculam do mesmo que são as religiões, regiões geográficas, e grupos raciais etc.; Classe sociais: pessoas que estão no mesmo nível social que estão divididos em classes, esse fator os consumidores têm o mesmo comportamento.

O fator social está classificado em grupo de referência e a família. Grupo de referência: são um grupo de pessoas que podem influência no pensamento do consumidor sobre um determinado produto ou serviço, dentro deste grupo são classificados os grupos informais que são as pessoas que a gente tem mais intimidade família, amigos etc., já o grupo formal são pessoas como grupo religiosos, sindicatos, grupo de apoio etc.; Família: são pessoas que tem poder maior de influenciar o indivíduo no seu ato de compra de um produto ou serviço, à passar do tempo os participantes assumem determinados papéis sociais onde isso fazem a eles a escolherem determinado produto ou serviço.

O fator pessoal que é composta pela idade, ocupação, condição econômica, estilo de vida, 
personalidade. Idade: ao longo do tempo as pessoas começam até uma mudança de desejo e necessidade sobre o consumo de produtos e serviço; Ocupação: a profissão exercida por cada pessoa implica também diretamente nos seus comportamentos de consumo; Condições econômicas: são o que implica diretamente no consumo das pessoas, onde e o patrimônio, crédito etc.; Estilo de vida: as opiniões e o posicionamento de uma marca de algum produto ou serviço no mercado poderão ter uma influência grande na decisão de compra do consumidor. Personalidade: cada pessoa tem uma personalidade diferente, onde essa diferença levará a ela ao um determinado produto, influenciando assim seu comportamento no mercado.

E por último o fator psicológico que está classificado em motivação, percepção, aprendizagem, crenças e atitudes. Motivação: o desejo da pessoa por um determinado produto que tem uma intuição de satisfazer sua necessidade e de desejo de consumo; Percepção: onde o consumidor faz uma análise, selecionando determinados produtos através de informação recebidas, onde irá escolher através da necessidade que ela está sofrendo naquele instante; Aprendizagem: Experiência adquirida através dos produtos anteriores que já foi consumido, isso implicará no comportamento de consumo das pessoas; Crenças e atitudes: a maneira de como as pessoas se comportam em determinadas escolhas de produto.

O fator econômico e uma delas onde ele implica diretamente na decisão de compra do consumidor, por conta de salários, empregos, inflação, etc., onde ele pode aumenta ou diminuir o poder de decisão de compra do consumidor. De acordo com Trevisan (2001) os especialistas em marketing das organizações deverão estuda como os consumidores mercado estão se comportando, ser o produto ou serviço ofertado está dando retorno, além disso deve analisar seus concorrentes através do desempenho deles no mercado, diante disso prevendo o que pode ser ameaças e está preparado para enfrenta.

Compreender o consumidor é uma função essencial do marketing para que ele possa cumprir plenamente seus objetivos no desenvolvimento, na produção e na colocação no mercado de bens e serviços apropriados e capazes de satisfazer as necessidades e desejos dos consumidores, contribuindo, assim, efetivamente para o sucesso do negócio.

Para a captação de novos ingressos as IES devem focar e analisa muito na forma de como seu público alvo se comporta no mercado, para que possa identificar os fatores que os influenciam nas suas tomadas de decisão e a partir disso elaborar novos métodos de prender a atração dos mesmos.

\section{METODOLOGIA}

O estudo é de natureza básica, exploratória, descritivo com abordagem qualitativa. A pesquisa exploratória consiste em assuntos que tenham problemas buscando investigar o contexto que está sendo abordado. Esse tipo de pesquisa tem como finalidade proporcionar a intimidade profunda do pesquisador que está aplicando a pesquisa com o assunto abordado (MARCONI et al., 2010).

Abordagem qualitativa e adequado à investigação descritiva à medida que se observa, descreve e classifica. A análise qualitativa apresenta certas características particulares. É válida, sobretudo, na elaboração das deduções específicas sobre um acontecimento ou uma variável de inferência precisa, e não em inferências gerais.

Sendo um estudo exploratório de caráter bibliográfico, foram utilizadas plataformas virtuais, como o 
Google Acadêmico e o Scielo, a fim de encontrar artigos que estão vinculados com a temática, é também sites na internet para estabelecer uma interface. Para a realização deste estudo teve como base autores que abordassem sobre o assunto, para que assim contribuiu para a estrutura desse estudo. Quanto aos critérios de inclusão foram utilizados apenas artigos e sites disponíveis em português, que abordem a temática de forma clara e objetiva. Já na parte da exclusão, publicações literaturas que não tivesse vínculo com o tema a ser pesquisado.

Através da seleção de artigos e sites que se aborda de forma clara o tema apresentado, onde foi feito uma observação minuciosa dos artigos para que não houvesse dúvidas sobre cada dado coletado. Quanto a organização e análise dos dados serão utilizados, a fundamentação teórica, a interpretação dos resultados acerca de leituras flutuantes de obras referentes ao objeto de estudo do trabalho proposto.

\section{RESULTADOS E DISCUSSÃO}

De acordo com Aléssio et al. (2010), os fatores que predominam nas escolhas dos estudantes em uma IES, são a estrutura da instituição e as instalações onde se encontra, de tal forma acaba sendo um fator atrativo para os calouros mas uns dos pontos negativos que podem fazer com que os estudantes não ingressar naquela instituição são os valores da mensalidade onde o implica diretamente na sua decisão de escolha, que na maioria das vezes são os próprios estudantes que acatam com os gastos para sua formação acadêmica, isso vem mostrando que os novos universitários estão se amadurecendo cada vez mais para o mercado, onde então os outros fatores trazem um peso menor na sua escolha.

Oliveira et al. (2018) explicam que o fator que teve mais poder de influência sobre os alunos foram o fator econômico onde entra a questão das mensalidades nas IES, cursos que são ofertados pela instituição. Dentre outros que os engloba estão relacionados aos fatores são os turnos dos cursos que estão sendo ofertados, para que isso não provoque um choque com o horário de trabalho dos mesmos.

De acordo com Soares (2008), o fator que os jovens recebem mais influência é o fator social, onde um grupo de referência que são pessoas formadas em determinada área estendem sua opinião sobre o curso, o mesmo identificou também na sua pesquisa que a ambiente família tem pouco poder de influência e isso acaba sendo um impacto menor na decisão do estudante sobre a IES.

Em pesquisa que foi realizada, identificou que $69 \%$ das escolhas dos estudantes estão mais vinculados com os fatores de grupos de referência', 'Infraestrutura', 'Programas de Bolsas e Financiamentos' e 'Relação Preço/Qualidade' onde se tem um poder maior de influência para eles, e o fator do preço que é a questão das mensalidades dos cursos que são ofertados pelas as IES.

Bergamo et al. (2010) ressaltam que as instituições de ensino superior não foquem somente na característica de ensino, mais também se preocupassem em outros fatores que se tornem uma maneira atrativa para captação de novos alunos como a parte financeira que acabam sendo um dos problemas mais enfrentados pelos estudantes, a localidade onde se encontra a instituição interferem um pouco na decisão do mesmo.

Para a construção desse tópico foi procurado artigos que abordassem essa temática, onde os 
resultados obtidos pelos autores anteriores foram analisados e discutido, revelando assim os fatores que influencia os estudantes a escolher uma instituição de ensino superior para ingressar e começa sua vida acadêmica profissional.

\section{CONCLUSÕES}

Esse artigo teve com objetivos específicos analisar os fatores que levam as pessoas a escolher uma Instituição de Ensino Superior. Descrever o cenário atual do ensino superior no Brasil; descrever os aspectos centrais do comportamento do consumidor. Onde os resultados desses termos específicos foram alcançados na parte transcorridos deste estudo.

Em relevância o estudo ajudará as pessoas a terem um planejamento mais adequado na escolha da IES, dessa forma as IES deverão ter mais enfoque nesses fatores, onde assim poderão auxiliarem os mesmos a não terem dificuldades nas suas escolhas proporcionando uma facilidade maior para a entrada de novos acadêmicos nas instituições. Como é de extrema importância conhecer esses fatores e se aprofunda mais neles pois implicam diretamente na vida acadêmica dos jovens levando a uma dificuldade ou uma facilidade de escolha.

\section{REFERÊNCIAS}

ALÉSSIO, S. C.; DOMINGUES, M. J. C. S.; SCARPIN, J. E.. Fatores Determinantes na Escolha por uma Instituição de Ensino Superior do Sul do Brasil. In: SIMPÓSIO DE EXCELÊNCIA EM GESTÃO E TECNOLOGIA, 7. Anais. Rio de Janeiro, 2010.

BERGAMO, F. V.; PONCHIO, M. C.; ZAMBALDI, F.; GIULIANI, A. C.. De Prospect a aluno: fatores influenciadores da escolha de uma instituição de ensino superior. Revista Base de Administração e Contabilidade da UNISINOS, v.7, n.3, p.182-193, 2010.

INEP. Instituto Nacional de Estudos e Pesquisas Educacionais Anísio Teixeira. Dados do Censo da Educação Superior as Universidades Brasileiras Representam 8\% da Rede, mas concentram 53\% das Matrículas. Brasília: INEP, 2018.

INEP. Instituto Nacional de Estudos e Pesquisas Educacionais Anísio Teixeira. Sinopse Estatística da Educação Superior 2017. Brasília: INEP, 2018.

LARENTIS, F.. Comportamento do consumidor e marketing de relacionamento. IESDE BRASIL, 2009.

MARCONI, M. A.; LAKATOS, E. M.. Fundamentos de metodologia científica. 7 ed. São Paulo: Atlas, 2010.
MARQUES, M. A.. Comportamento do consumidor na escolha de uma instituição de ensino superior (IES). Monografia (Especialização em Marketing) - Centro Universitário Ritter dos Reis, 2015.

OLIVEIRA, T. R. F. G.; GIROLETTI, D. A.; JEUNON, E. E.. Fatores de influência na escolha da Instituição de Ensino Superior: Estudo de Caso em uma IES Privada de Minas Gerais. Revista Brasileira de Pesquisas de Marketing, Opinião e Mídia, São Paulo, v.11, n.2, p.141-158, 2018.

PRIDE, W. M.; FERREL, O. C.. Marketing: conceitos e estratégias. Rio de Janeiro: LTC, 2001.

RODRIGUES, M. G.. Educação Superior: tecnologia, inovação e criatividade. Brasília: ABMES, 2016.

SEBRAE. Como entender consumidores e planejar estratégias mais inteligentes. SEBRAE, 2019.

SOARES, F. L. B.; MILAN, G. S.. Fatores de decisão que influenciam a escolha no Ensino Superior. In: SEMINÁRIOS EM ADMINISTRAÇÃO. Anais. SEMEAD, 2008.

TREVISAN, R. M.. Marketing em Instituições Educacionais. Revista PEC, v.2, n.1, p.93-103, 2001.

A CBPC - Companhia Brasileira de Produção Científica (CNPJ: 11.221.422/0001-03) detém os direitos materiais desta publicação. Os direitos referem-se à publicação do trabalho em qualquer parte do mundo, incluindo os direitos às renovaç̃oses, expansões e disseminações da contribuiç̃o, bem como outros direitos subsidiários. Todos os trabalhos publicados eletronicamente poderão posteriormente ser publicados em coletâneas impressas sob coordenação da Sustenere Publishing, da Companhia Brasileira de Produção Científica e seus parceiros autorizados. Os (as) autores (as) preservam os direitos autorais, mas não têm permissão para a publicação da contribuição em outro meio, impresso ou digital, em português ou em tradução. 